\title{
Perceived Benefits of Incorporating Yoga into Classroom Teaching: Assessment of the Effects of "Yoga Tools for Teachers"
}

\author{
David Dapeng Chen ${ }^{*}$, Linda Pauwels ${ }^{2}$ \\ ${ }^{1}$ California State University, Fullerton, CA, USA \\ ${ }^{2}$ Azusa Pacific University, Azusa, CA, USA \\ Email: "dapchen@fullerton.edu
}

Received 16 July 2014; revised 17 August 2014; accepted 25 August 2014

Copyright (C) 2014 by authors and Scientific Research Publishing Inc.

This work is licensed under the Creative Commons Attribution International License (CC BY). http://creativecommons.org/licenses/by/4.0/

(c) (i) Open Access

\begin{abstract}
With rising health issues among children and adolescents in America such as obesity and diabetes, getting physically active becomes ever more important. Yoga, as an ancient system of exercise, has a great potential to teach children to be mindful of factors that impact their health and improve their total well-being. The purpose of this study was to examine the perceived benefits of incorporating yoga-based activities into classroom teaching as a result of implementing the Yoga Ed. Tools for Teachers program. One hundred and three physical education and classroom teachers were trained by certified Yoga Ed. instructors for two days. These teachers, in turn, implemented the yoga-based activities for $\mathbf{5}$ - 15 minutes daily for a year. At the completion of this period, questionnaires from 550 parents and 661 students as well as 103 teachers were analyzed. Triangulation of the data provided solid evidence suggesting that yoga-based activities produced perceived benefits in such areas as mental well-being, social well-being, physical well-being, and daily behaviors. The data analyses also revealed barriers teachers encountered during implementation and what they did to overcome these barriers. The results were discussed with regard to their future implications for yoga programs appropriate for schools in the United States (US).
\end{abstract}

\section{Keywords}

Yoga, Yoga Ed. Tools, Physical Education Teaching

\section{Introduction}

The current health status of U.S. school children causes great concerns for educators and parents. Lack of regu-

"Corresponding author.

How to cite this paper: Chen, D. D., \& Pauwels, L. (2014). Perceived Benefits of Incorporating Yoga into Classroom Teaching: Assessment of the Effects of "Yoga Tools for Teachers". Advances in Physical Education, 4, 138-148. 
lar physical activity is believed to contribute to the childhood obesity epidemic which is associated with premature mortality rates in the US (U.S. Department of Health and Human Services, 2000; Zimmerman et al., 2013). In addition, lack of physical activity also causes many other related health issues among children in the US such as increased stress, poor sleep, and decline in mental health (McPhie \& Rawana, 2012). Childhood and adolescence pose more and more stressors in today's society when the demands of a situation exceed an individual's ability to cope with and resolve the problem, resulting in emotional, behavioral, and cognitive disturbances that can adversely affect a person's physical and mental well-being (McCance, Forshee, \& Shelby, 2006). Under stress many young people resort to unhealthy ways of coping such as over-eating and use of drugs, resulting in health crises (Kottler \& Chen, 2011).

Because children spend many hours at schools where infrastructure already exists for physical activity, school-based programs may contribute to reversing the negative trends in physical activity. In fact, schools have been asked to help foster health habits and increase students' level of physical activity (Pate et al., 2006; Sallis et al., 1997). In addition, physical education programs in schools have been recommended as ideal settings to begin the early promotion of health and emphasize the importance of physical activity (U.S. Department of Health and Human Services, 2000). While the benefits of traditional physical activity programs are still evident, more and more educators have resorted to non-traditional and mindfulness interventions for their holistic effects on the health of children (e.g., Burke, 2010).

Yoga, as an ancient system of exercise, is being used more and more by people of all ages to promote overall health and fitness. There is also a progressive trend toward use of yoga as a mind-body complementary and alternative medicine intervention to improve specific physical and mental health conditions. Yoga has been recommended as a great supplement to current physical activities at schools because it emphasizes individual abilities rather than competition, making it attractive to all children, including those with physical limitations and lack of involvement in organized sports. Yoga also has the potential to reduce obesity and other health issues. Since yoga is hailed as a mindfulness exercise (Burke, 2010), it enhances one's self-awareness including breathing, posture, diet, and behaviors, and it has the potential to influence the whole person. Research with adults and limited research on children has provided some evidence that yoga practice leads to improvements in one's life in all the areas examined in the student questionnaire. Yoga practiced by adults reduces anxiety (Brown \& Gerbarg, 2005), and improves relaxation (Smith, Hancock, Blake-Mortimer, \& Eckert, 2007; Waelde, Thompson, \& Gallagher-Thompson, 2004). A recent review of research on the effects of yoga practice on children produced moderate evidence suggesting benefits for cardiovascular health, physical functioning, and behavior (see Galantino et al., 2008 for a review). Yoga research on children also points to improved attention and emotional control (Jensen \& Kenny, 2004).

Although it would be ideal for physical education teachers to deliver yoga classes on a regular basis, with the tightening of school budgets, it can be attractive for classroom teachers to deliver physical activity curricula. Research shows that enabling classroom teachers to deliver physical activity could be an economic solution to a daunting health crisis faced by our nation's youngsters (Sherman, Tran, \& Alves, 2010). It is natural for classroom teachers to feel intimidated by incorporating yoga into their curriculum, but given proper training, it is quite feasible. Yoga appears to be simply a stretching activity, but the variety and sequencing of postures coupled with the practice of deep breathing creates an extremely diverse and effective method of enhancing a range of health-related fitness skills.

The purpose of this study was to examine the perceived benefits of incorporating yoga-based activities into classroom teaching as a result of implementing the Yoga Ed. Tools for Teachers program. A Carol M. White Physical Education Program (PEP) grant was awarded to The Accelerated School (TAS). The grant funded Yoga $\mathrm{Ed}^{\mathrm{TM}}$ trainings for classroom teachers, physical education teachers and yoga instructors. The Tools for Teachers is a very important component of Yoga Ed. trainings that was offered to both physical education and classroom teachers with the expectation that they would incorporate 5 - 15 minutes yoga-based activities into their curriculum and serve as a model for fitness and health.

\section{Method}

\subsection{Participants}

Completed surveys from 103 teachers, 550 parents, and 661 students (average age $=9.71$; SD $=2.98$ ) were processed and as many as 54 returned questionnaires were disqualified for their incompleteness or modifications 
(see Table 1 for the demographics of student participants). All the participants agreed to participate in the study and received and returned a signed letter of informed consent/assent. Teachers were trained by certified yoga instructors from Yoga Ed. funded by the PEP grant. Students were from mid-to-low socioeconomic status public schools or from a charter school in the western United States).

\subsection{The Yoga Ed. Tools for Teachers Workshop}

The Yoga Ed. Tools for Teachers is a very important component of Yoga Ed. It was offered to physical education and non-physical educational teachers from other schools. Instructors from Yoga Ed. offered a 2-day workshop in which participating physical education or classroom teachers learned yoga-based activities designed for the K-12 classroom. Under the supervision of certified Yoga Ed. instructors, classroom and physical education teachers learned such important techniques as breathing, postures, yoga-based games, and visualization. They also learned how to teach their students to relax, become more responsible, and become physically active through teaching and personal modeling. When teachers finished their 2-day training, they signed a contract to deliver simple 5 - 15 minutes yoga-based exercises on a daily basis. This program did not require any previous yoga experience. Implementation of the yoga-based activities in schools required no extra space or equipment. In addition to yoga-based activities, effective behavior and class management techniques were also taught during the workshop.

\subsection{Development of Written Surveys}

The authors, who served as external evaluators of the effectiveness of Yoga Ed. Tools for Teachers, developed four written questionnaires in both English and Spanish to survey teachers, students, and their parents. This triangulation of data was to insure that the perceptions of three perspectives could converge on similar conclusions. The student surveys were designed to determine the students' perceptions of the benefits they had received from participation in the yoga-based activities, organized by their teachers, who had been trained by certified Yoga Ed. instructors. These benefits included: 1) mental well-being (e.g., relaxation, concentration, calmness, selfconfidence, joy and happiness), 2) social well-being (e.g., ability to get along with others, listening skills), 3) physical well-being (postures, sleep, fatigue, eating and diet), and 4) positive behaviors (e.g., responsibility, behavioral changes) (see Table 2 for details). These items of assessment are consistent with the areas of study that have dealt with yoga.

Table 1. Demographics of 661 student participants.

\begin{tabular}{ccc}
\hline Age & Females $(\mathrm{n}=328)$ & Males $(\mathrm{n}=333)$ \\
5 & 26 & 16 \\
6 & 22 & 26 \\
7 & 29 & 32 \\
8 & 46 & 35 \\
9 & 75 & 83 \\
10 & 25 & 20 \\
11 & 27 & 21 \\
12 & 22 & 24 \\
13 & 36 & 42 \\
14 & 14 & 12 \\
15 & 1 & 2 \\
16 & 3 & 4 \\
17 & 4 & 2 \\
18 & 0 & 2 \\
19 & 0 & 2 \\
20 & 2 & 4 \\
21 & 2 & 0 \\
\hline
\end{tabular}


Table 2. Student self survey questions.

If you have additional comments, please use the space on the back of the survey.

1 = Strongly disagree. 2 = Disagree. 3 = Neutral. 4 = Agree. 5 = Strongly agree.

Comparing myself to how I was before my classroom teacher began using the yoga tools in the classroom,

1. I have become more relaxed in daily living.

2. I have had fewer or no behavioral problems at school.

3. I have become more responsible in managing my daily tasks.

4. I am more focused on school work

5. I can sleep better.

6. I am more energetic.

7. I am more aware of what I eat.

8. I have gained more knowledge about nutrition.

9. I start to eat more healthy foods.

10. I am getting along better with my family and friends.

11. I am a better listener today.

12. I can calm down more quickly once I feel upset.

13. I know more about my body.

14. I have better body postures.

15. I feel more confident in myself.

16. I am happier and laugh more often.

17. I enjoy school work and sports more than before.

18. I like myself more.

The parent questionnaire was based on the same 18 items from the student survey questionnaire, because the researchers wanted to ensure that parents who had many opportunities to observe their children would have similar observations of the changes in their children's behaviors and well-being.

The teacher survey questionnaire consisted of eight Likert-scale questions and two open-ended questions. The eight Likert-scale questions represented the same four areas of benefits practice of yoga was supposed to bestow upon the students, with the first question addressing the quality of training they had received to prepare for the implementation of the yoga-based activities. The two open-ended questions were designed to assess the barriers they had encountered during the implementation and what they had done to overcome these barriers. This information is valuable to teachers who will carry on the same tasks in the future (see Table 3).

\subsection{Procedures}

Testing materials and procedures were approved by the institutional review board and the local school district boards. The teachers were trained between April 2007 and August 2008 by certified Yoga Ed. instructors. The teachers signed a contract to implement the yoga-based activities as part of their curriculum. At the end of one-year implementation, they agreed to send their surveys back to TAS. The students and their parents agreed to complete the questionnaires and return them to TAS.

\subsection{Data Analysis}

Data analyses for the Likert-scale questions were analyzed using SPSS Version 19. We ran basic descriptive statistics to assess the perceived benefits of yoga activities. Open-ended questions were analyzed by examining the content of their answers and identifying the themes that emerged from the answers given by 102 teachers.

\section{Results}

All the survey data were analyzed with SPSS Version 19. The researchers first generated descriptive statistics. A 
Table 3. Post-implementation teacher survey (Yoga Ed. Tools Program).

1 = Strongly disagree. 2 = Disagree. 3 = Neutral. 4 = Agree. 5 = Strongly agree.

Please put a number in the designated space to indicate your level of agreement the following statements.

1. The training I received at Yoga Ed/The Accelerated School has proven sufficient for me to implement the yoga program.

2. The yoga program I implemented has improved the cognitive functioning and hence school performance of the recipients.

3. The yoga program I implemented has enabled my students to focus better on important tasks at hand.

4. The yoga program I implemented has improved the social skills of my students.

5. The yoga program I implemented has improved the emotional maturity of my students.

6. The yoga program I implemented has improved the self-esteem of the students.

7. The yoga program I implemented has contributed to a reduction of behavioral problems among my students.

8. The yoga program I implemented has enabled my students to become better in caring for themselves.

Please answer the following questions carefully.

What kinds of barriers did you encounter as you implemented the yoga program?

What did you do when you encountered these barriers?

score of 3 is interpreted as a neutral response. Scores 4 and 5 represent positive responses while 1 and 2 negative responses. The mean score of 3.5 and above indicates a positive effect.

\subsection{Student Survey Results}

The results of the student surveys showed that yoga practice had produced positive changes in all the areas surveyed, since their average scores were all above 3.5. When we examined the negative and positive responses, the overwhelming responses were positive. The most notable changes students had identified in the 18-question survey included the area of mental well-being and physical well-being (see Table 4 and Table 5).

The student survey data indicated that yoga practice yielded positive changes in the domains of mental, emotional, physical, and interpersonal growth. The most notable positive changes students identified in themselves as a result of yoga practice include joy (mean $=4.18$ ), self-esteem (mean $=4.21$ ), enthusiasm (mean $=4.04$ ), confidence (mean $=4.17)$, knowledge of human body $($ mean $=4.02)$, posture (mean $=4.01)$, energy $($ mean $=4.0)$, interpersonal relationships $($ mean $=4.02)$, sleep $($ mean $=3.90)$, and concentration $($ mean $=3.92)$.

\subsection{Parent Survey Results}

The parent survey data demonstrated that, in general, yoga practice led to positive perceived changes in their students in all the surveyed domains of mental, emotional, physical, and interpersonal growth. However, the most notable areas of improvement include joy $($ mean $=4.04)$, self-esteem $($ mean $=4.04)$, enthusiasm $($ mean $=$ $4.04)$, confidence $($ mean $=4.04)$, concentration (mean $=3.91)$, and sleep $($ mean $=3.89)$. It appears that parent perceptions of the benefit yoga practice created were less positive that those by students themselves (see results in Table 6 and Table 7).

\subsection{Teacher Survey Results}

There were a total of 103 teachers who participated in the study. They received yoga training, delivered the instruction, and completed surveys. The majority of the teachers believed that the implementation of the yoga program had delivered the predicted benefits for their students (see Table 8 and Table 9).

Teacher surveys did not assess individual students' improvement in emotional, mental and physical well-being, but provided their overall assessment of improvement in emotional, mental, and physical well-being. It can be seen from Table 8 and Table 9 that teachers believed that the yoga training they received was adequate for delivering yoga instruction (mean $=4.17$ ), and the implementation of yoga instruction in their classrooms was conduciveto producing positive changes in students' concentration (4.17), social skills (mean $=4.03$ ), emotional maturity $($ mean $=4.03)$, self-esteem $(4.03)$, and self-care $($ mean $=4.08)$. 
Table 4. Results from student surveys based on 18 questions.

\begin{tabular}{ccccc}
\hline Questions & Total responses & Positive responses & Neutral responses & Negative responses \\
\hline Relaxation & 660 & 440 & 153 & 67 \\
Behaviors & 660 & 409 & 164 & 87 \\
Responsibility & 659 & 437 & 152 & 70 \\
Concentration & 652 & 449 & 133 & 70 \\
Better sleep & 645 & 436 & 114 & 95 \\
Less fatigue & 648 & 457 & 131 & 60 \\
Eating awareness & 654 & 420 & 152 & 82 \\
Knowledge in nutrition & 656 & 419 & 149 & 88 \\
Eating better & 654 & 426 & 148 & 40 \\
Friends and relatives & 655 & 469 & 137 & 59 \\
Better listening & 650 & 447 & 147 & 92 \\
Calmness & 660 & 439 & 129 & 57 \\
Knowledge of human body & 650 & 463 & 130 & 56 \\
Posture & 632 & 458 & 118 & 40 \\
Confidence & 588 & 448 & 100 & 49 \\
More joy & 585 & 444 & 92 & 69 \\
Enthusiasm & 584 & 420 & 95 & 40 \\
Self-esteem & 575 & 435 & 100 & 50 \\
\hline
\end{tabular}

Table 5. Descriptive statistics for student surveys Yoga Ed. tools based on 18 questions.

\begin{tabular}{cccc}
\hline & N & Mean & SD \\
\hline Relaxation & 660 & 3.87 & 1.118 \\
Behaviors & 660 & 3.77 & 1.141 \\
Responsibility & 659 & 3.87 & 1.081 \\
Concentration & 652 & 3.92 & 1.073 \\
Better sleep & 645 & 3.90 & 1.252 \\
Less fatigue & 648 & 4.00 & 1.092 \\
Eating awareness & 654 & 3.80 & 1.161 \\
Knowledge in nutrition & 656 & 3.80 & 1.162 \\
Eating better & 654 & 3.86 & 1.125 \\
Friends and relatives & 655 & 4.02 & 1.076 \\
Better listening & 650 & 3.94 & 1.056 \\
Calmness & 660 & 3.85 & 1.179 \\
Knowledge of human body & 650 & 4.02 & 1.093 \\
Posture & 632 & 4.01 & 1.112 \\
Confidence & 588 & 4.17 & 1.052 \\
More joy & 585 & 4.18 & 1.058 \\
Enthusiasm & 584 & 4.04 & 1.198 \\
Self-esteem & 575 & 4.21 & 1.091 \\
\hline
\end{tabular}


Table 6. Results from parent surveys based on 18 questions.

\begin{tabular}{ccccc}
\hline Questions & Total responses & Positive responses & Neutral responses & Negative responses \\
\hline Relaxation & 545 & 340 & 159 & 46 \\
Behaviors & 538 & 328 & 163 & 47 \\
Responsibility & 548 & 343 & 165 & 40 \\
Concentration & 547 & 382 & 132 & 33 \\
Better sleep & 548 & 358 & 153 & 37 \\
Less fatigue & 541 & 323 & 164 & 54 \\
Eating awareness & 545 & 336 & 145 & 64 \\
Knowledge in nutrition & 547 & 326 & 158 & 63 \\
Eating better & 546 & 305 & 175 & 66 \\
Friends and relatives & 543 & 350 & 156 & 37 \\
Better listening & 547 & 353 & 138 & 56 \\
Calmness & 547 & 315 & 173 & 59 \\
Knowledge of human body & 488 & 325 & 141 & 22 \\
Posture & 487 & 318 & 137 & 32 \\
Confidence & 491 & 371 & 94 & 26 \\
More joy & 494 & 372 & 96 & 33 \\
Enthusiasm & 495 & 370 & 92 & 30 \\
Self-esteem & 496 & 373 & 93 & \\
\hline
\end{tabular}

Table 7. Descriptive statistics for parent surveys.

\begin{tabular}{cccc}
\hline & N & Mean & SD \\
\hline Relaxation & 546 & 3.72 & 0.951 \\
Behaviors & 540 & 3.75 & 1.016 \\
Responsibility & 550 & 3.77 & 0.932 \\
Concentration & 548 & 3.91 & 0.924 \\
Better sleep & 549 & 3.89 & 0.976 \\
Less fatigue & 543 & 3.71 & 1.006 \\
Eating awareness & 547 & 3.70 & 1.011 \\
Knowledge in nutrition & 549 & 3.70 & 1.038 \\
Eating better & 548 & 3.63 & 1.055 \\
Friends and relatives & 546 & 3.83 & 0.961 \\
Better listening & 548 & 3.74 & 0.992 \\
Calmness & 548 & 3.63 & 0.986 \\
Knowledge of human body & 491 & 3.84 & 0.892 \\
Posture & 490 & 3.79 & 0.905 \\
Confidence & 492 & 4.04 & 0.919 \\
More joy & 495 & 4.04 & 0.917 \\
Enthusiasm & 495 & 4.04 & 0.934 \\
Self-esteem & 496 & 4.01 & 0.902 \\
\hline
\end{tabular}


Table 8. Results from teachers’ post-implementation surveys based on 8 questions.

\begin{tabular}{ccccc}
\hline Questions & Total responses & Positive responses & Neutral responses & Negative responses \\
\hline Yoga Ed. training & 103 & 81 & 17 & 5 \\
Cognitive benefit & 96 & 63 & 29 & 4 \\
Attentional focus & 103 & 77 & 23 & 21 \\
Social skills & 97 & 69 & 19 & 7 \\
Emotional maturity & 101 & 72 & 24 & 3 \\
Self-esteem & 88 & 61 & 24 & 6 \\
Behavioral improvements & 94 & 64 & 24 & 3 \\
\hline
\end{tabular}

Table 9. Descriptive statistics for post-implementation teacher surveys.

\begin{tabular}{cccc}
\hline Questions & N & Mean & SD \\
\hline Yoga Ed. training & 103 & 4.17 & 0.909 \\
Cognitive benefit & 96 & 3.98 & 0.951 \\
Attentional focus & 102 & 4.17 & 0.880 \\
Social skills & 97 & 4.03 & 0.984 \\
Emotional maturity & 101 & 3.99 & 1.015 \\
Self-esteem & 88 & 4.03 & 0.928 \\
Behavioral improvements & 94 & 3.99 & 0.978 \\
Self-care & 95 & 4.08 & 0.883 \\
\hline
\end{tabular}

Teacher survey data also solicited answers from teachers about the barriers they encountered during implementation. The most commonly cited barriers include space restrictions, student resistance, time constraints, parental resistance/misunderstandings, and lack of support from peer teachers (see Table 10).

Most of the participants provided steps they had taken to reduce the impact of or remove the barriers while implementing the programs. The most outstanding themes that emerged from their answers include creative adaptation, self-help/training, improving communication with parents and students, seeking help from administration, and starting with something easy and manageable (see Table 11).

\section{Discussion}

The current study assessed the perceived benefits of participating in yoga-based activities incorporated into classroom teaching as a result of implementing the Yoga Ed. Tools for Teachers program. The data of the perceived benefits were obtained from the teachers who delivered yoga instruction, the parents whose children were involved in the intervention program, and the students who participated in the Yoga program. The results of this study showed that practicing yoga has been viewed as instrumental to enhancing mental focus, reducing negative behaviors, increasing physical vigor, improving awareness and practice of eating, enhancing communication with family and friends, and enhancing emotional resilience and joy.

Data triangulation involving students, parents, and teachers provide extra assurance that the assessed effects are verifiable and reliable. The survey data from students, parents, and teachers all showed that yoga practice may have facilitated development of concentration and attention in a school setting. These data are consistent with previous studies that found benefits of yoga practice with children with attention problems (e.g., Abadi et al., 2008; Harrison et al., 2004; Peck et al., 2005). Even though we did not collect data of student academic achievement in this study, perceived benefits in concentration and attentional focus should contribute to academic success.

The results from this study have clearly indicated that yoga practice improved emotional health, as indicated 
Table 10. Barriers encountered during the implementation of the yoga program.

\begin{tabular}{cc}
\hline Emergent themes & Number of times mentioned \\
\hline Lack of space & 21 \\
Lack of time (curriculum related) & 20 \\
Student resistance/Peer issues & 15 \\
Parental resistance/Misunderstandings & 14 \\
Lack of resources & 11 \\
Curriculum issues & 6 \\
Resistance from administration & 5 \\
Lack of training/knowledge & 5 \\
\hline
\end{tabular}

Table 11. Steps taken to remove or reduce the impact of implementation barriers.

\begin{tabular}{cc}
\hline Emergent themes & Number of times mentioned \\
\hline Integrate into current curriculum & 10 \\
Approach parents & 7 \\
Started with breathing & 6 \\
Starting with small groups/Easy exercises & 5 \\
Used artistic innovations & 5 \\
Self-help/Take extra classes & 4 \\
Better communication with students & 4 \\
Persistence/Motivation & 4 \\
Do it outside first & 3 \\
Seek yoga support group & 3 \\
Seek administrative help & 2 \\
\hline
\end{tabular}

by increases in perceived self-confidence, level of joy, and self-esteem. These emotional indicators suggest that students who practice yoga may feel less stressed and more resilient when confronted with stressful situations. This finding also confirms the previous studies suggesting the benefits of yoga in reducing anxiety and enhancing positive affect (e.g., Gloeckner \& Stück, 2005; Platania-Solazzo et al., 1992). Considering the stress children and adolescents are faced with at school on a daily basis (Kottler \& Chen, 2011), yoga can serve as a great remedy for reducing negative affect and distress.

The current study also suggests that yoga practice has contributed to improved physical well-being. Data from three sources have supported the claim that yoga practice has facilitated knowledge of human body, eating awareness, and body posture as reported by the student participants, their parents, and their teachers. The survey data showed that teachers, students, and parents all agree that participation in school-based yoga program for a year produced positive behavioral changes.

The current study has much to offer for future school-based yoga activity programs. First, teachers with minimum training in yoga can produce large effects on students. Second, students who get support from parents can produce positive changes in their lives. Third, it is important to have a structure in which students are exposed to healthy way of living.

Despite the significance of the current study, the generalizability of its results is restricted by its limitations. First, it was not a controlled and randomized study. The way each teacher delivered yoga instruction was not controlled for and verified. Second, the reliability and validity of surveys used for assessing the effects of Yoga instruction had not been established prior to testing. Finally, it was assumed that the parents and students who were involved in the study had been given equivalent instructions as to how to fill out the surveys and this assumption was too difficult to be confirmed. However, this present study is the first study that contained a large population that involved triangulation of data and involved predominantly Hispanic and African populations with limited access to yoga. Future researchers should use a randomized and controlled design if possible. More 
information should be gathered about the qualifications of teachers and more hard data should be collected to correlate yoga practice with GPA, health indices and so on.

\section{Conclusion}

The current study has much to offer for future school-based yoga activity programs. First, teachers with minimum training in yoga who incorporate daily yoga-based techniques in the classroom can produce large effects on students. Second, students who get support from parents can produce positive changes in their lives. Third, it is important to have a structure in which students are exposed to healthy ways of living. And most important, the data provided solid evidence suggesting that yoga-based activities produced perceived benefits in students' mental well-being, social well-being, physical well-being, and daily behaviors.

\section{References}

Abadi, M. S., Madgaonkar J., \& Venkatesan, S. (2008). Effect of Yoga on Children with Attention Deficit/Hyperactivity Disorder. Psychological Studies, 53, 154-159.

Brown, R., \& Gerbarg, P. (2005). Sudarshan Kria Yogic Breathing in the Treatment of Stress, Anxiety, and Depression: Part II-Clinical Applications and Guidelines. Journal of Alternative and Complementary Medicine, 11, 711-717. http://dx.doi.org/10.1089/acm.2005.11.711

Burke, C. (2010). Mindfulness-Based Approaches with Children and Adolescents: A Preliminary Review of Current Research in an Emergent Field. Journal of Child and Family Studies, 19, 133-144.

http://dx.doi.org/10.1007/s10826-009-9282-x

Galantino, M., Galbavy, R., \& Quinn, L. (2008). Therapeutic Effects of Yoga for Children: A Systematic Review of the Literature. Pediatric Physical Therapy, 20, 66-80. http://dx.doi.org/10.1097/PEP.0b013e31815f1208

Gloeckner, N., \& Stück, M. (2005). Yoga for Children in the Mirror of the Science: Working Spectrum and Practice Fields of the Training of Relaxation with Elements of Yoga for Children. Early Child Development and Care, 175, 371-377. http://dx.doi.org/10.1080/0300443042000230537

Harrison, L. J., Manocha, R., \& Rubia, K. (2004). Sahaja Yoga Meditation as a Family Treatment Programme for Children with Attention Deficit-Hyperactivity Disorder. Clinical Child Psychology and Psychiatry, 9, 479-497. http://dx.doi.org/10.1177/1359104504046155

Jensen, P., \& Kenny, D. (2004). The Effects of Yoga on the Attention and Behavior of Boys with Attention-Deficit/Hyperactivity Disorder (ADHD). Journal of Attention Disorders, 7, 205-216. http://dx.doi.org/10.1177/108705470400700403

Kottler, J., \& Chen, D. D. (2011). Stress Management and Prevention: Daily Applications (2nd ed.). New York, NY: Routledge.

McCance, K., Forshee, B., \& Shelby, J. (2006). Stress and Disease. In K. L. McCance, \& S. E. Huether (Eds.), Pathophysiology: The Biologic Basis for Disease in Adults and Children (pp. 311-332). St. Louis: Mosby.

McPhie, M., \& Rawana, J. (2012). Unravelling the Relation between Physical Activity, Self-Esteem and Depressive Symptoms among Early and Late Adolescents: A Mediation Analysis. Mental Health and Physical Activity, 5, 43-49.

http://dx.doi.org/10.1016/j.mhpa.2012.03.003

Pate, R. R., Davis, M. G., Robinson, T. N., Stone, E. J., McKenzie, T. L., \& Young, J. C. (2006). Promoting Physical Activity in Children and Youth: A Leadership Role for Schools: A Scientific Statement from the American Heart Association Council on Nutrition, Physical Activity, and Metabolism (Physical Activity Committee) in Collaboration with the Councils on Cardiovascular Disease in the Young and Cardiovascular Nursing. Circulation, 114, 1214-1224. http://dx.doi.org/10.1161/CIRCULATIONAHA.106.177052

Peck, H. L., Kehle, T. J., Bray, M. A., \& Theodore, L. A. (2005). Yoga as an Intervention for Children with Attention Problems. School Psychology Review, 34, 415-424.

Platania-Solazzo, A., Field, T. M., Blank, J., Seligman, F., Kuhn, C., Schanberg, S., \& Saab, P. (1992). Relaxation Therapy Reduces Anxiety in Child and Adolescent Psychiatric Patients. Acta Paedopsychiatrica, 55, 115-120.

Sallis, J. F., McKenzie, T. L., Alcaraz, J. E., Kolody, B., Faucette, N., \& Hovell, M. F. (1997). The Effects of a 2-Year Physical Education Program (SPARK) on Physical Activity and Fitness in Elementary School Students. American Journal of Public Health, 87, 1328-1334. http://dx.doi.org/10.2105/AJPH.87.8.1328

Sherman, C., Tran, C., \& Alves, Y. (2010). Elementary School Classroom Teacher Delivered Physical Education: Costs, Benefits, and Barriers. The Physical Educator, 67, 2-12.

Smith, C., Hancock, H., Blake-Mortimer, J., \& Eckert, K. (2007). A Randomized Comparative Trial of Yoga and Relaxation to Reduce Stress and Anxiety. Complementary Therapies in Medicine, 15, 77-83.

U.S. Department of Health and Human Services (2000). Healthy People 2010: Understanding and Improving Health (2nd 
ed). Washington, DC: US Department of Health and Human Services.

Waelde, L., Thompson, L., \& Gallagher-Thompson, D. (2004). A Pilot Study of a Yoga and Meditation Intervention for Dementia Caregiver Stress. Journal of Clinical Psychology, 60, 677-687. http://dx.doi.org/10.1002/jclp.10259

Zimmerman, S., Kramer, K., \& Trowbridge, M. (2013). Overcoming Legal Liability Concerns for School-Based Physical Activity Promotion. American Journal of Public Health, 103, 1962-1967. http://dx.doi.org/10.2105/AJPH.2013.301319 
Scientific Research Publishing (SCIRP) is one of the largest Open Access journal publishers. It is currently publishing more than 200 open access, online, peer-reviewed journals covering a wide range of academic disciplines. SCIRP serves the worldwide academic communities and contributes to the progress and application of science with its publication.

Other selected journals from SCIRP are listed as below. Submit your manuscript to us via either submit@scirp.org or Online Submission Portal.
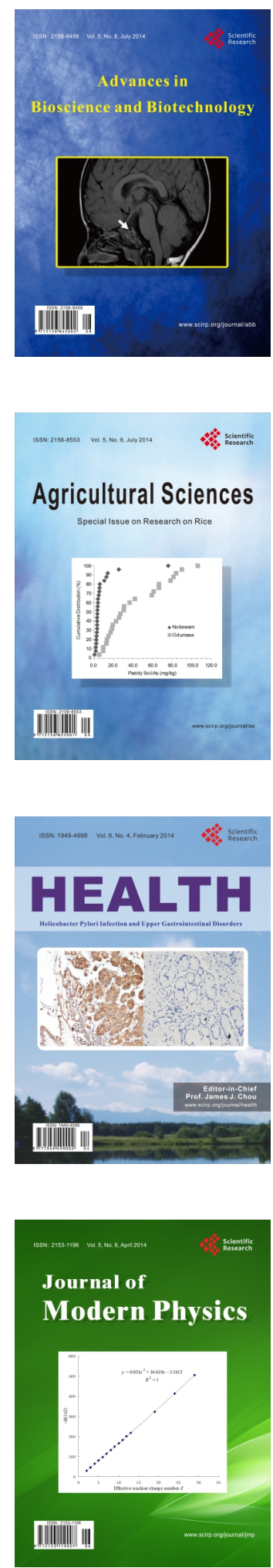
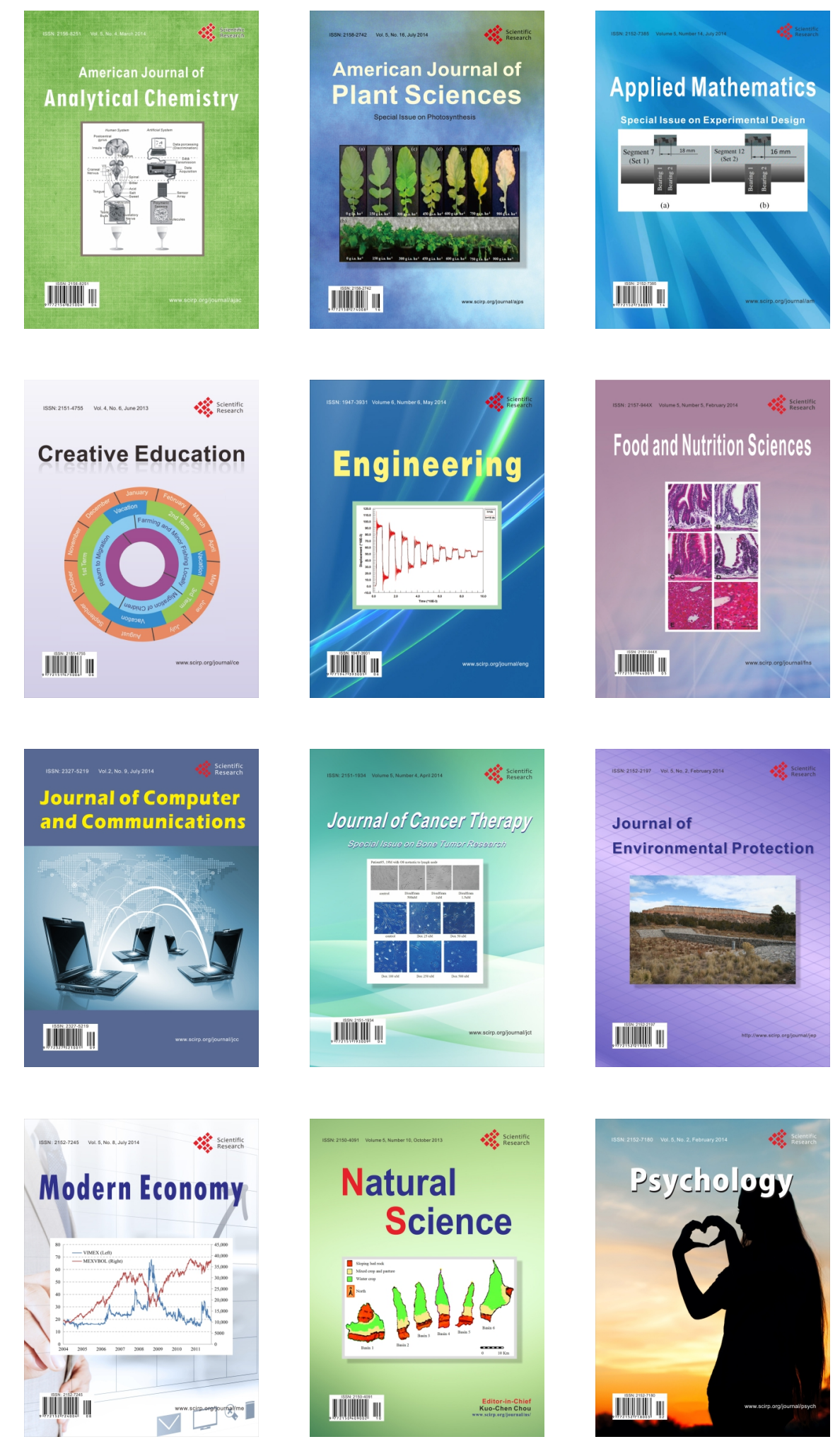